OPEN ACCESS

Edited by: Amy Lasek, University of Illinois at Chicago, United States

Reviewed by:

Kazuma Sakamoto,

Nagoya University, Japan

Gonzalo Herradon,

CEU San Pablo University, Spain

*Correspondence:

Caroline Biojone caroline.biojone@helsinki.fi Eero Castrén eero.castren@helsinki.fi

Received: 25 February 2021 Accepted: 25 June 2021 Published: 22 July 2021

Citation: Lesnikova A, Casarotto P, Moliner R, Fred SM, Biojone $C$ and Castrén $E$ (2021) Perineuronal Net Receptor PTP $\sigma$ Regulates Retention of Memories.

Front. Synaptic Neurosci. 13:672475. doi: 10.3389/fnsyn.2021.672475

\section{Perineuronal Net Receptor PTPo Regulates Retention of Memories}

\author{
Angelina Lesnikova, Plinio Casarotto, Rafael Moliner, Senem Merve Fred, \\ Caroline Biojone* and Eero Castrén*
}

Neuroscience Center, HiLIFE, University of Helsinki, Helsinki, Finland

Perineuronal nets (PNNs) have an important physiological role in the retention of learning by restricting cognitive flexibility. Their deposition peaks after developmental periods of intensive learning, usually in late childhood, and they help in long-term preservation of newly acquired skills and information. Modulation of PNN function by various techniques enhances plasticity and regulates the retention of memories, which may be beneficial when memory persistence entails negative symptoms such as post-traumatic stress disorder (PTSD). In this study, we investigated the role of PTPo [receptor-type tyrosineprotein phosphatase $\mathrm{S}$, a phosphatase that is activated by binding of chondroitin sulfate proteoglycans (CSPGs) from PNNs] in retention of memories using Novel Object Recognition and Fear Conditioning models. We observed that mice haploinsufficient for PTPRS gene $\left(\mathrm{PTP}^{+/-}\right)$, although having improved short-term object recognition memory, display impaired long-term memory in both Novel Object Recognition and Fear Conditioning paradigm, as compared to WT littermates. However, PTP $\sigma^{+/-}$mice did not show any differences in behavioral tests that do not heavily rely on cognitive flexibility, such as Elevated Plus Maze, Open Field, Marble Burying, and Forced Swimming Test. Since PTPo has been shown to interact with and dephosphorylate TRKB, we investigated activation of this receptor and its downstream pathways in limbic areas known to be associated with memory. We found that phosphorylation of TRKB and PLC $\gamma$ are increased in the hippocampus, prefrontal cortex, and amygdaloid complex of $\mathrm{PTP}^{+/-}$mice, but other TRKB-mediated signaling pathways are not affected. Our data suggest that PTPo downregulation promotes TRKB phosphorylation in different brain areas, improves short-term memory performance but disrupts long-term memory retention in the tested animal models. Inhibition of PTP $\sigma$ or disruption of PNN-PTP $\sigma$ TRKB complex might be a potential target for disorders where negative modulation of the acquired memories can be beneficial.

Keywords: memory, perineuronal nets, plasticity, PNNs, PTPRS, BDNF, Ntrk2, TrkB

\section{INTRODUCTION}

Perineuronal nets (PNNs) are complex extracellular matrix structures consisting of a core protein and multiple glycosaminoglycan chains, such as chondroitin sulfate proteoglycans (CSPGs) and heparan sulfate proteoglycans (HSPGs; Deepa et al., 2006; Testa et al., 2019). They surround somata and proximal dendrites of certain types of neurons (Hockfield and McKay, 1983), 
being particularly enriched around parvalbumin-positive interneurons (PV+; Kosaka and Heizmann, 1989; Fawcett et al., 2019). Perineuronal nets are well-recognized regulators of plasticity in the central nervous system (CNS) which stabilize and consolidate the system (Banerjee et al., 2017; Christensen et al., 2021), and play an indispensable role in learning and memory (Wang and Fawcett, 2012; Sorg et al., 2016; Shen, 2018). Interference with perineuronal net structure by chondroitinase $\mathrm{ABC}$ (chABC) digestion of their sugar chains or genetic knockdown of PNN components has been shown to promote plasticity in multiple paradigms, including ocular dominance (Pizzorusso et al., 2002), drug-induced conditioned place preference (Xue et al., 2014; Slaker et al., 2015) and fear learning (Gogolla et al., 2009; Banerjee et al., 2017; Pignataro et al., 2017; Shi et al., 2019).

CSPGs have been reported to exert their inhibitory action on neuronal plasticity by binding to protein tyrosine phosphatase sigma (РTP $\sigma$ ), a transmembrane receptor (Shen et al., 2009; Coles et al., 2011). PTP $\sigma$ is a multi-functional molecule playing a role in various processes in the nervous system, such as cell proliferation and adhesion, synapse organization, synaptic transmission, axonal regeneration, and hypothalamuspituitary axis functioning (Elchebly et al., 1999; Thompson et al., 2003; Takahashi et al., 2011; Horn et al., 2012; Ji et al., 2015; Han et al., 2018, 2020; Bomkamp et al., 2019). Importantly, PTP $\sigma$ downregulation has been demonstrated to reduce CSPG deposition induced by glial scar formation following axonal injury (Luo et al., 2018; Tran et al., 2018). However, the interaction of PTP $\sigma$ with CSPGs constituting specifically perineuronal nets has not been studied. We have recently found that the PNN-PTP $\sigma$ complex exerts its inhibitory action on neuronal plasticity by restricting the signaling of neurotrophic receptor tyrosine kinase 2 (TRKB; Lesnikova et al., 2021). TRKB is a receptor for brain-derived neurotrophic factor (BDNF) and a well-known activator of plasticity in the brain (Minichiello et al., 1999; Castrén and Antila, 2017; Umemori et al., 2018). РТР $\sigma$ has been found to interact with and dephosphorylate TRK receptors, including TRKB (Faux et al., 2007; Kurihara and Yamashita, 2012). We found that genetic deficiency of PTP $\sigma$ increases phosphorylation of TRKB and promotes cortical plasticity at the network level (Lesnikova et al., 2021). We also showed that chABC-induced plasticity in the adult brain requires intact $\mathrm{TRKB}$ expression in PV+ interneurons, a neuronal class whose mode of function is particularly dependent on PNNs. There, we propose a model where, under normal conditions in the adult brain, perineuronal nets bind to PTP $\sigma$ and promote dephosphorylation of TRKB and restriction of its activity, while reduction of interaction between PNNs and PTP $\sigma$ or PTP $\sigma$ and TRKB enhances the ability of BDNF to phosphorylate TRKB and promote plasticity (Lesnikova et al., 2021).

Here, we set out to further investigate the effects of PTP $\sigma$ downregulation on neuronal plasticity. In particular, our aim was to characterize the molecular profile of enhanced plasticity induced by PTP $\sigma$ genetic deficiency and to reveal any changes in the behavioral phenotype of animals haploinsufficient for PTPRS gene.

\section{MATERIALS AND METHODS}

\section{Animals}

Adult BALB/c mice heterozygous for PTPRS gene $\left(\mathrm{PTP}^{+/-}\right)$ and their wild-type (WT) littermates of both sexes were used for the experiments. $\mathrm{PTP}^{-1-}$ mice is a hardly viable phenotype with severe growth deficits and a 2-3\% survival rate (Elchebly et al., 1999; Wallace et al., 1999). Animals with such major developmental problems often develop compensatory mechanisms that may complicate phenotyping. Our previous study found that only partial genetic deficiency of PTP $\sigma$ produces a robust phenotype of enhanced plasticity at molecular and network levels (Lesnikova et al., 2021). Therefore, we continued using $\mathrm{PTP}^{+/-}$mice in this study. The animals were grouphoused (2-5 animals per cage in type-2: $552 \mathrm{~cm}^{2}$ floor area, Tecniplast, Italy) under standard laboratory conditions with a 12-h light/dark cycle and access to food and water ad libitum. Behavioral experiments were carried out during the light phase of the cycle. All the procedures involving animals were carried out with the approval of the Experimental Animal Ethical Committee of Southern Finland (ESAVI/38503/2019).

\section{Antibodies}

The following antibodies were used in the study: anti-Akt rabbit polyclonal antibody (pAb; Cell Signaling Technology, \#9272); anti- $\beta$-Actin mouse monoclonal antibody (mAb; Sigma-Aldrich, \#A1978); anti-p44/42 MAPK (Erk1/2) rabbit pAb (Cell Signaling Technology, \#9102); anti-p70 S6 kinase rabbit pAb (Cell Signaling Technology, \#9202); anti-phospho-Akt rabbit mAb (Cell Signaling Technology, \#4056); anti-phospho-p44/42 MAPK (Erk1/2) rabbit mAb (Cell Signaling Technology, \#9101); antiphospho-p70 S6 kinase rabbit pAb (Cell Signaling Technology, \#9204); anti-phospho-PLC $\gamma 1$ rabbit pAb (Cell Signaling Technology, \#2821); anti-PLC $\gamma 1$ rabbit mAb (Cell Signaling Technology, \#5690); anti-phospho-TRKA (Tyr490)/TRKB (Tyr516) rabbit mAb (Cell Signaling Technology, \#4619); anti-PSD-93/anti-Chapsyn-110 mouse mAb (UC Davis/NIH NeuroMab Facility; anti-PSD-95 mouse mAb (UC Davis/NIH NeuroMab Facility); anti-synaptophysin (D35E4) rabbit mAb (Cell Signaling Technology, \#5461); anti-TRKB goat pAb (R\&D Systems, \#AF1494); secondary goat anti-mouse Alexa Fluor 568 antibody (Life Technologies, \#A11004); secondary goat anti-mouse horseradish peroxidase (HRP)-conjugated antibody (Bio-Rad, \#1705047); secondary goat anti-rabbit Alexa Fluor 647 antibody (Life Technologies, \#A21245); secondary goat anti-rabbit HRP-conjugated antibody (Bio-Rad, \#1705046), secondary rabbit anti-goat HRP-conjugated antibody (Invitrogen, \#611620).

\section{Brain Sample Collection and Processing}

For immunohistochemical analysis, the mice were anesthetized with $300 \mathrm{mg} / \mathrm{kg}$ pentobarbital mixed with $50 \mathrm{mg} / \mathrm{kg}$ lidocaine. They were transcardially perfused with PBS (137 mM NaCl, $10 \mathrm{mM}$ sodium phosphate, $2.7 \mathrm{mM} \mathrm{KCl}$; $\mathrm{pH}$ 7.4) followed by cold $4 \%$ PFA in PBS. The brains were removed and post-fixed in $4 \%$ PFA in PBS at $+4^{\circ} \mathrm{C}$ overnight. On the following day, the brains were cryoprotected in 30\% sucrose in phosphate buffer (PB; 
0.1 M PB without sodium chloride, $\mathrm{pH}$ 7.4) and left for 2 days at $+4^{\circ} \mathrm{C}$. After that, the brains were embedded into Tissue-Tek O.C.T. Compound (BioLab, \#4583) and cut into $40 \mu \mathrm{m}$ coronal sections using Cryostat (Leica Byosystems). The brain sections were stored in cryoprotectant solution (30\% ethylene glycol, 25\% glycerol in $0.05 \mathrm{M} \mathrm{PB}$ ) at $-20^{\circ} \mathrm{C}$ until further processing.

For the ELISA and Western blot analysis, the animals were euthanized by $\mathrm{CO}_{2}$, then the prefrontal cortex, hippocampus, and amygdaloid complex were dissected out of the fresh brain and immediately placed on dry ice. The samples were homogenized by sonication in NP lysis buffer $(137 \mathrm{mM} \mathrm{NaCl}$, $20 \mathrm{mM}$ Tris, 1\% NP-40, 10\% glycerol, $48 \mathrm{mM} \mathrm{NaF}$ ) containing a protease and phosphatase inhibitor mix (\#P2714 and \#P0044, Sigma Aldrich) and $2 \mathrm{mM} \mathrm{Na}_{2} \mathrm{VO}_{3}$. The homogenized samples were centrifuged for $15 \mathrm{~min}$ at $15,000 \times \mathrm{g}, 4^{\circ} \mathrm{C}$. The supernatant was collected and stored at $-80^{\circ} \mathrm{C}$ until further use. Protein quantification was done by colorimetric Lowry method using DC Protein Assay Kit (Bio-Rad, \#5000116) and the product of the colorimetric reaction read at $750 \mathrm{~nm}$ in a Varioskan Flash plate reader (Thermo Fisher Scientific).

\section{Immunohistochemical (IHC) Analysis}

For the Immunohistochemical (IHC) analysis, samples from 2 months old male and female mice were used. The samples were washed in PBST ( $137 \mathrm{mM} \mathrm{NaCl}, 10 \mathrm{mM}$ sodium phosphate, $2.7 \mathrm{mM} \mathrm{KCl}, 0.1 \%$ Tween 20; pH 7.4) $2 \times 5$ min and blocked in the blocking buffer (3\% BSA, 10\% normal goat serum, and $0.04 \%$ sodium azide in PBST) for $30 \mathrm{~min}$ at room temperature. After that, the samples were incubated in the primary anti-PSD95 and anti-synaptophysin antibodies mix (1:100 in the blocking buffer) at $+4^{\circ} \mathrm{C}$ for $48 \mathrm{~h}$. After that, the slices were washed in PBST $2 \times 5 \mathrm{~min}$ and incubated in secondary antibodies mix (goat anti-mouse Alexa Fluor 568 and goat anti-rabbit Alexa Fluor 647) at room temperature for $1 \mathrm{~h}$. After the incubation, the slices were washed in PBST $3 \times 10$ min and stored in $0.1 \mathrm{~PB}$ during mounting on slides. The mounting was done with DAKO fluorescence mounting medium (Agilent, \#S3023).

\section{Confocal Imaging and Image Analysis}

Brain slice imaging was performed using confocal microscope LSM 700 (Carl Zeiss) with $63 \times / 1.46$ M27 oil-immersed Plan Apochromat objective (Carl Zeiss, \# 420780-9971-000) and 3.0 digital zoom-in. A $Z$-stack containing six consecutive images with a distance of $0.5 \mu \mathrm{m}$ was obtained from each section. Colocalization analysis was performed with Zen Blue 2.1 software using Manders Overlap Coefficient (MOC; Manders et al., 1993). An average value over a $Z$-stack for each brain slice was evaluated, and then an average MOC value of four slices per animal was calculated for statistical analysis.

\section{Enzyme-Linked Immunosorbent Assay (ELISA)}

Samples from female mice 2-3 months old were used for this experiment. We assessed levels of TRKB phosphorylation (pTRKB) using a protocol previously described by Antila et al. (2014). A high-binding 96-well OptiPlate (Perkin Elmer) was coated with anti-TRKB antibody incubated in carbonate buffer
(57.4 mM sodium bicarbonate and $42.6 \mathrm{mM}$ sodium carbonate, $\mathrm{pH} 9.8) 1: 500$ at $4^{\circ} \mathrm{C}$ overnight. On the next day, the antibody was removed, and the wells were blocked using a blocking buffer containing 3\% bovine serum albumin (BSA; Sigma-Aldrich, \#A9647) in PBST (137 mM NaCl; $10 \mathrm{mM}$ sodium phosphate; $2.7 \mathrm{mM} \mathrm{KCl} ; 0.1 \%$ Tween-20; $\mathrm{pH} \mathrm{7.4)}$ for $2 \mathrm{~h}$. After that, homogenized and centrifuged brain lysates $(80 \mu \mathrm{g}$ of total protein) were transferred to the plate and incubated at $4^{\circ} \mathrm{C}$ overnight. On day 3 , the samples were removed, the plate was washed four times with PBST using a plate washer (Thermo Fisher Scientific Wellwash Versa), and anti-pTRKB antibody (1:1,000 in the blocking buffer) was incubated at $4^{\circ} \mathrm{C}$ overnight. On the final day, the antibody was removed, the plate was washed four times with PBST, and incubated with horseradish peroxidase (HRP)-conjugated antibody (1:5,000 in the blocking buffer) for $1 \mathrm{~h}$ at room temperature. The antibody was removed, the plate was washed four times with PBST, and HRP ECL substrate (Thermo Fisher Scientific, \#32209) was incubated in the plate for $3 \mathrm{~min}$. Chemiluminescence was measured using $1 \mathrm{~s}$ integration time in a Varioskan Flash plate reader (Thermo Fisher Scientific).

\section{Western Blot}

Samples from male and female mice (2 months old) were used for this experiment. Forty microgram of total proteins from each sample was heated in 2X Laemmli buffer (4\% SDS, $20 \%$ glycerol, $10 \%$ 2-mercaptoethanol, $0.02 \%$ bromophenol blue and $125 \mathrm{mM}$ Tris $\mathrm{HCl}, \mathrm{pH} 6.8$ ) for $5 \mathrm{~min}$ at $95^{\circ} \mathrm{C}$ and loaded to NuPAGE 4-12\% Bis-Tris Protein polyacrylamide gels (Invitrogen, \#NP0323BOX). After electrophoresis, the proteins were transferred to a polyvinylidene difluoride (PVDF) membrane, blocked in the blocking buffer for $1 \mathrm{~h}(3 \%$ BSA in Tris-PB: TBST, $20 \mathrm{mM}$ Tris- $\mathrm{HCl} ; 150 \mathrm{mM} \mathrm{NaCl}$; $0.1 \%$ Tween-20; $\mathrm{pH}$ 7.6) and incubated with the primary antibody diluted $1: 1,000$ in the blocking buffer overnight at $4^{\circ} \mathrm{C}$. The membranes were subsequently incubated in HRP-conjugated secondary antibodies diluted in the blocking buffer $(1: 10,000)$ for $1 \mathrm{~h}$ at room temperature. The signal was detected using enhanced chemiluminescent (ECL) HRP substrate WesternBright Quantum (Advansta, \#K-12042) in a CCD camera (G:Box Chemi, Syngene). The levels of phosphoproteins analyzed by Western blot were normalized by total levels of the corresponding proteins; the levels of total TRKB, PSD-93, and PSD-95 were normalized by B-actin. PSD-95 samples from PFC were not normalized due to low detection signal from the housekeeping protein.

\section{Novel Object Recognition Test}

Male and female mice (3-4 months old) were used for these experiments. NOR test was performed in a transparent arena $(39 \times 20 \times 16 \mathrm{~cm})$ where two identical objects (white plastic ping-pong balls glued to $50-\mathrm{ml}$ Falcon tube caps) were located (adapted from Casarotto et al., 2021). The animals were allowed to explore the objects for $15 \mathrm{~min}$ on three consecutive days (training sessions). At the test session ( $4 \mathrm{~h}$ or 5 days after the last training session to assess short-term or long-term memory, respectively) one of the old objects was replaced by a new one (black rubber squash ball glued to 50-ml Falcon tube caps), and 
the animals were allowed to explore both objects for $5 \mathrm{~min}$. The number of interactions with the objects was calculated, and the difference between the visits to the new object and the old object ( $\mathrm{fB}-\mathrm{fA}$ ) was used to assess memory. The total number of visits $(\mathrm{f} A+\mathrm{fB})$ was used to assess total exploratory activity. Two independent cohorts of animals were used to assess short-term and long-term memory.

\section{Fear Conditioning}

Male mice (4-7 months old) were used for this experiment. This cohort of mice was older than the rest of the mice used in the other experiments. However, previous studies in the literature found no difference in the rodent performance of these age groups as compared to 2-3 months old animals in the cued fear conditioning paradigm (Stoehr and Wenk, 1995; Oler and Markus, 1998; Houston et al., 1999; Kaczorowski and Disterhoft, 2009). Mice were subjected to fear conditioning in a squared arena $\mathrm{A}$ ( $23 \mathrm{~cm}$ width, $35 \mathrm{~cm}$ height) with a metal grid on the floor and transparent acrylic glass walls, with continuous background white noise and 100 lux illumination. On day 1 , the animals received five foot shocks $(0.6 \mathrm{~mA}, 1 \mathrm{~s})$ preceded by a 30-s sound cue each (latency to the first foot shock: $150 \mathrm{~s}$, time between the last foot shock and the end of the trial: $30 \mathrm{~s}$, inter-shock interval: $30-120 \mathrm{~s}$, total session length: $8 \mathrm{~min} 45 \mathrm{~s}$ ). On day 10, the mice were first placed in a new arena B (same size as arena A but with plastic gray floor and plastic black walls), and freezing in response to the sound cue was measured (cue retrieval). Two hours later, the mice were placed in the same context where fear conditioning took place (arena A), and freezing in response to the sound cue was measured (context + cue retrieval). Behavior was counted as freezing if the mouse was not moving for at least $3 \mathrm{~s}$, and measurements were done automatically by TSE system software.

\section{Elevated Plus Maze}

Male mice (3 months old) were used for this experiment. The apparatus consisted of a central zone $(5 \times 5 \mathrm{~cm})$, two open arms $(30 \times 5 \mathrm{~cm})$, and two closed arms $(30 \times 5 \mathrm{~cm})$ surrounded by transparent acrylic glass walls (15 cm height). The maze was elevated $40 \mathrm{~cm}$ above the floor. The illumination was set to $\sim 150$ lux. The animal was placed in the center of the arena and allowed to explore the maze for $5 \mathrm{~min}$. The animal activity was tracked automatically by the Noldus EthoVision XT 8 system.

\section{Open Field Test}

Male mice ( 3 months old) were used for this experiment. The test was carried out in a squared arena $(30 \mathrm{~cm}$ wide) with transparent walls $(20 \mathrm{~cm})$ and white floor. The illumination was set at $\sim 100$ lux. The mice were placed in the center of the arena and allowed to explore it freely for $5 \mathrm{~min}$. The activity was tracked automatically by Noldus EthoVision XT 8 system.

\section{Marble Burying Test}

Male mice ( 3 months old) were used for this experiment. 12 glass marbles were evenly distributed on a fresh $5 \mathrm{~cm}$-deep wood chip bedding in a rectangular plastic arena similar in size to the mouse home cage $(39 \times 20 \times 16 \mathrm{~cm})$. The mice were given $15 \mathrm{~min}$ to explore the marbles, and the number of buried marbles was counted. A marble was considered buried if at least $2 / 3$ of its surface was covered with bedding chips (Njung'e and Handley, 1991).

\section{Forced Swimming Test}

Male mice ( 3 months old) were used for this experiment. The animals were placed in a $5119-\mathrm{cm} \emptyset$ glass cylinder with a $20-\mathrm{cm}$ water column at room temperature $\left(\sim 22^{\circ} \mathrm{C}\right)$ for $6 \mathrm{~min}$. Total time spent floating during the last $4 \mathrm{~min}$ (immobility time) was used for the analysis.

\section{Statistical Analysis}

The data were analyzed using Graph Pad Prism 6 software. Parametric tests were preferentially used when possible, non-parametric tests were used when the values were discrete or homoscedasticity was not observed. ROUT test was used to identify outliers (Motulsky and Brown, 2006). Detailed information on statistical tests and values is provided in Table 1. Differences between groups were considered statistically significant when $p<0.05$. Data in the figures are presented as mean \pm SEM.

\section{RESULTS}

We have recently demonstrated that PTP $\sigma$ restricts TRKB signaling in vitro and in vivo through dephosphorylation, and we have shown that genetic PTP $\sigma$ deficiency increases basal TRKB phosphorylation and activates network level-plasticity in the visual cortex (Lesnikova et al., 2021). However, it is unknown which intracellular signaling pathways mediate the effects of the increase in PTRKB induced by the lack of PTP $\sigma$. In order to investigate the molecular profile of changes triggered by PTP $\sigma$ deficiency, we carried out a biochemical analysis of tissue from different brain areas extracted from $\mathrm{PTP}^{+/-}$mice and compared it with brain tissue from their wild-type littermates.

First, we confirmed that the effect of PTP $\sigma$ haploinsufficiency on TRKB phosphorylation is not brain region-specific. We checked pTRKB levels in the prefrontal cortex (PFC), hippocampus (HPC), and amygdala (AMG) of $\mathrm{PTP}^{+/-}$mice by ELISA, and observed around 50\% increase in pTRKB as compared to WT littermates in all of the brain regions tested (Figure 1A). To confirm that these changes in pTRKB are driven by increased phosphorylation and not by alterations in the TRKB expression, we tested levels of total TRKB protein in the $\mathrm{PTP}^{+/-}$mouse samples by Western blot and detected no changes in total TRKB expression (Figure 1B). Next, we analyzed phosphorylation levels of phospholipase C gamma 1 (PLC $\gamma 1$ ), protein kinase B (Akt), extracellular signal-regulated kinase 1 and 2 (Erk1 and Erk2), and ribosomal protein S6 kinase beta-1 (p70S6 kinase), which are known to be activated downstream of TRKB. We observed a significant increase in pPLC $\gamma 1$ (Figure 1C) but not in pAkt, pErk1, pErk2, or p-p70S6 kinase (Figures 1D-G correspondingly) in PFC, HPC, and AMG of PTP $\sigma^{+/-}$mice. Finally, we checked 
TABLE 1 | Statistical analysis of the experimental data.

\begin{tabular}{ll}
\hline Graph & Test \\
\hline $1 \mathrm{~A}$ & Two-way ANOVA: \\
& Interaction: $F_{(2,33)}=0.1561, p=0.8561$ \\
& Brain area: $F_{(2,33)}=0.1561, p=0.8561$ \\
& Genotype: $F_{(1,33)}=11.29, p=0.0020$ \\
& Post hoc Sidak's multiple comparisons test: \\
& PFC: $p=0.1357$ \\
& HPC: $p=0.3362$ \\
& AMG: $p=0.1056$ \\
& \\
& Two-way ANOVA: \\
& Interaction: $F_{(2,33)}=0.08055, p=0.9228$ \\
& Brain area: $F_{(2,33)}=0.08055, p=0.9228$ \\
& Genotype: $F_{(1,33)}=0.07902, p=0.7804$
\end{tabular}

$1 C$ Two-way ANOVA:

Interaction: $F_{(2,27)}=0.9691, p=0.3922$

Brain area: $F_{(2,27)}=0.1508, p=0.8607$

Genotype: $F_{(1,27)}=6.439, p=0.0172$

Post hoc Sidak's multiple comparisons test:

PFC: $p=0.4620$

HPC: $p=0.0766$

AMG: $p=0.9180$

1D Two-way ANOVA:

Interaction: $F_{(2,34)}=0.2987, p=0.7437$

Brain area: $F_{(2,34)}=0.2987, p=0.7437$

Genotype: $F_{(1,34)}=0.4211, p=0.5208$

$1 \mathrm{E}$ Two-way ANOVA:

Interaction: $F_{(2,34)}=0.5062, p=0.6072$

Brain area: $F_{(2,34)}=0.5062, p=0.6072$

Genotype: $F_{(1,34)}=0.04609, p=0.8313$

$1 F \quad$ Two-way ANOVA:

Interaction: $F_{(2,25)}=1.811, p=0.1843$

Brain area: $F_{(2,25)}=1.811, p=0.1843$

Genotype: $F_{(1,25)}=0.4599, p=0.5039$

Two-way ANOVA:

Interaction: $F_{(2,30)}=3.266, p=0.0521$

Brain area: $F_{(2,30)}=3.266, p=0.0521$

Genotype: $F_{(1,30)}=0.2616, p=0.6127$

$1 \mathrm{H}$ Two-way ANOVA:

Interaction: $F_{(2,35)}=1.144, p=0.3302$

Brain area: $F_{(2,35)}=1.144, p=0.3302$

Genotype: $F_{(1,35)}=0.8513, p=0.3625$

11 Two-way ANOVA:

Interaction: $F_{(2,33)}=0.1788, p=0.8371$

Brain area: $F_{(2,33)}=0.1788, p=0.8371$

Genotype: $F_{(1,33)}=0.7467, p=0.3938$

\section{$N$ per group}

WT PFC: 5

PTP ${ }^{+/-}$PFC: 7

WT HPC: 7

PTP $\sigma^{+/-}$HPC: 7

WT AMG: 6

PTP $\sigma^{+/-}$AMG: 7

WT PFC: 5

PTP $\sigma^{+/-}$PFC: 9

WT HPC: 5

PTP $\sigma^{+/-}$HPC: 7

WT AMG: 5

PTP $\sigma^{+/-}$AMG: 8

WT PFC: 5

PTP $\sigma^{+/-}$PFC: 8

WT HPC: 3

PTP $\sigma^{+/-}$HPC: 6

WT AMG: 4

PTP $\sigma^{+/-}$AMG: 7

WT PFC: 5

PTP $\sigma^{+/-}$PFC: 8

WT HPC: 4

PTP $\sigma^{+/-}$HPC: 9

WT AMG: 5

PTP $\sigma^{+/-}$AMG: 9

WT PFC: 5

PTPo ${ }^{+/-}$PFC: 8

WT HPC: 4

PTP $\sigma^{+/-}$HPC: 9

WT AMG: 5

PTP ${ }^{+/-}$AMG: 9

WT PFC: 4

PTP $\sigma^{+/-}$PFC: 7

WT HPC: 4

PTP $\sigma^{+/-}$HPC: 8

WT AMG: 3

PTP $\sigma^{+/-}$AMG: 5

WT PFC: 3

PTP $\sigma^{+/-}$PFC: 8

WT HPC: 4

PTP $\sigma^{+/-}$HPC: 9

WT AMG: 4

PTP $\sigma^{+/-}$AMG: 8

WT PFC: 5

PTP $\sigma^{+/-}$PFC: 9

WT HPC: 4

PTP $\sigma^{+1-}$ HPC: 9

WT AMG: 5

PTP $\sigma^{+/-}$AMG: 9

WT PFC: 5

PTP $\sigma^{+/-}$PFC: 9

WT HPC: 4

PTP $\sigma^{+/-}$HPC: 9
TABLE 1 | Continued

\begin{tabular}{ll}
\hline Graph Test & N per group \\
\hline & WT AMG: 5 \\
& PTP $\sigma^{+/-}$AMG: 9
\end{tabular}

2A Mann-Whitney:

WT: 7

Short-term Discrimination Index: $U=1$,

PTP $\sigma^{+/-}: 6$

$p=0.0035$

Short-term Exploratory Activity: $U=15$,

$p=0.4254$

2B Mann-Whitney:

long-term Discrimination Index: $U=13.5$,

$p=0.0006$

long-term Exploratory Activity: $U=45.5$,

$p=0.2360$

2C Repeated-measures two-way ANOVA:

Interaction: $F_{(2,18)}=4.189, p=0.0321$

Time: $F_{(2,18)}=1.562, p=0.2369$

Genotype: $F_{(1,9)}=3.262, p=0.1044$

Post hoc Sidak's multiple comparisons test:

Within group comparisons:

WT acquisition $\times$ WT cue: $p=0.7679$

WT acquisition $\times$ WT context + cue: $p=0.2129$

WT cue $\times$ WT context + cue: $p=0.0376$

$\mathrm{PTP}^{+/-}$acquisition $\times \mathrm{PTP}^{+/-}$cue:

$p=0.3982$

$\mathrm{PTP}^{+/-}$acquisition $\times \mathrm{PTP}^{+/-}$context + cue:

$p=0.1572$

$\mathrm{PTP}^{+/-}$cue $\times \mathrm{PTP}^{+/-}$context + cue:

$p=0.9249$

Between groups comparisons:

WT acquisition $\times \mathrm{PTP}^{+/-}$acquisition:

$p=0.9909$

WT cue $\times \mathrm{PTP}^{+/-}$cue: $p=0.7342$

WT context + cue $\times \mathrm{PTP}^{+/-}$context + cue:

$p=0.0123$

3A Open Arm Time: Unpaired $t$ test: $t_{(12)}=1.027$,

$p=0.3245$

Open Arm Entries: Mann-Whitney: $U=24.5$,

$p>0.9999$

Closed Arm Entries: Mann-Whitney: $U=24.5$,

$p>0.9999$

3B Mann-Whitney:

$U=19.5, p=0.5408$

WT: 7

PTP $\sigma^{+/-}: 7$

3C Unpaired $t$ test:

$t_{(12)}=0.2450, p=0.8106$

WT: 7

$\mathrm{PTP}^{+/-}: 7$

3D Unpaired $t$ test: $t_{(12)}=0.2565, p=0.8019$

WT: 7

PTP $\sigma^{+/-}: 7$

levels of postsynaptic density proteins 93 and 95 (PSD-93 and PSD-95) which are known to be important for synaptic plasticity but did not find any difference in their expression (Figures 1H,I).

Since PTP $\sigma$ is also known to be involved in synapse organization, acting specifically on excitatory synapses (Takahashi et al., 2011; Takahashi and Craig, 2013; Li et al., 2015b; Han et al., 2018, 2020), we assessed the number of excitatory synapses in $\mathrm{PTP}^{+/-}$mice and WT littermates 
by immunostaining pre- (synaptophysin) and post-synaptic (PSD-95) markers, in hippocampal slices. We evaluated the colocalization of the pre- and post-synaptic markers using MOC and did not find any difference between the genotypes (Supplementary Figure 1).

Considering the important role of BDNF-TRKB for various brain functions, including learning and memory (Thoenen, 1995; Minichiello et al., 1999; Cunha et al., 2010), we set out to investigate the behavioral phenotype of $\mathrm{PTP}^{+/-}$ mice. We started with the Novel Object Recognition test, a cognitive test that evaluates memory-related performance in rodents (Dere et al., 2007). When tested $4 \mathrm{~h}$ after the last training session, $\mathrm{PTP}^{+/-}$mice exhibited significantly more interest towards the new object as opposed to the old object, suggesting improved short-term memory (Figure 2A). This result was similar to the findings by Horn et al. (2012) who observed improved short-term recognition memory in full PTP $\sigma$ knock-out mice $\left(\mathrm{PTP}^{-l-}\right)$. However, when tested 5 days after the last training session, $\mathrm{PTP}^{+/-}$mice demonstrated essentially no difference in exploration between the old and the new object, which indicates that they have significantly impaired long-term recognition memory as opposed to the WT, who remembered the old object and tended to visit the new one more often (Figure 2B). No difference in total exploratory activity was found between the genotypes in either of the tests.

In order to understand if the impaired long-term memory observed in the $\mathrm{PTP}^{+/-}$mice was specific to recognition memory or if it was a more generalized memory impairment, we tested those mice also in the fear conditioning model using a protocol that involves both context- and cue-dependent memory components. In the fear conditioning experiment (Figure 2C), the fear-related memory was established by pairing foot shocks (unconditioned stimulus) with the context (transparent cage with metallic grid floor) and cue (tone). The conditioned response (freezing) was measured immediately after the foot shocks (acquisition) and again 10 days later (retrieval). WT and $\mathrm{PTP} \sigma^{+/-}$mice displayed similar levels of freezing right after the foot shocks, demonstrating comparable acquisition of fear memories in both genotypes. Ten days later, we tested memory retrieval triggered by the cue presented either in a novel context (black cage with a smooth floor) or in the same context where the foot shocks were previously applied (conditioned context, transparent cage with metallic grid floor). Statistical analysis indicates that there was no significant change in the levels of freezing when the acquisition was compared with either of the retrieval sessions, in both genotypes, suggesting that the fear memory did not spontaneously fade away with time. Interestingly, in WT but not in the $\mathrm{PTP}^{+/-}$mice, the fear response triggered by the cue in the retrieval session was potentiated by the context, since freezing was greatly increased in the conditioned context in comparison with the novel context in the WT group (indicated by the sharp sign in Figure 2C). On the other hand, $\mathrm{PTP}^{+/-}$mice responded similarly to the cue presented in the novel or the conditioned context. Finally, the freezing response triggered by the cue combined with conditioned context (cue + context) was significantly higher in the WT compared to the $\mathrm{PTP} \sigma^{+/-}$mice (indicated by the asterisk in Figure 2C), reinforcing the evidence that PTP deletion might attenuate the retrieval of certain types of longterm memories.

Altogether, the behavioral data suggest that PTP $\sigma$ may play a role in memory processes as its deficiency facilitates shortterm memory and deteriorates long-term memory retention in the behavior paradigms we tested. However, it is important to keep in mind that the Novel Recognition Memory and Fear conditioning behavioral data are not directly comparable due to the intrinsic characteristics of each model and other methodological differences caused by practical limitations in obtaining animal cohorts. One limitation of the current study was the variation in the sex and age of mice used in each behavioral model. However, all the animals tested belonged to the adult group (2-7 months old) and thus were no longer in the age of juvenile plasticity, which otherwise could have affected the performance. Whenever mice from both sexes were tested, no difference was found between the sex groups. Moreover, the data we obtained from different groups of animals tested were not contradictory but rather complementary and harmonic. Nevertheless, we kindly ask the reader to keep in mind this limitation of the study.

Finally, we ran a behavior battery to test whether PTP $\sigma^{+/-}$ mice have any behavioral abnormalities other than those related to learning and memory (Figure 3 ). The tests were separated by at least $24 \mathrm{~h}$ and carried out in the following order: marble burying, elevated plus maze, open field, and forced swimming test. Interestingly, $\mathrm{PTP}^{+/-}$mice displayed no abnormalities in any of these tests, indicating no difference in the levels of anxiety, total exploratory activity, and locomotion as compared to the WT.

\section{DISCUSSION}

We have previously observed that the plasticity-promoting effects of PNN removal are dependent on TRKB signaling in PV interneurons and that PTP $\sigma$ acts as an agent mediating the opposing effects that perineuronal nets and TRKB have on plasticity (Lesnikova et al., 2021). We demonstrated that PNNPTP $\sigma$-TRKB interaction in parvalbumin interneurons plays a particularly important role, as the chondroitinase ABC effect on network plasticity is abolished in mice lacking full-length TRKB in PV+ cells (PV-TRKB ${ }^{+/-}$mice; Lesnikova et al., 2021). Therefore, it is plausible that $\mathrm{PV}+$ interneurons may contribute to the plastic phenotype of РТР $\sigma$ mice as they are the major class of neurons expressing PNNs, and are known to be strongly affected by $\mathrm{PNN}$ modulation. $\mathrm{PV}+$ cells play a crucial role in many cognitive processes, including learning and memory (Korotkova et al., 2010; Kim et al., 2016), and manipulation of $\mathrm{PV}+$ neurons modulates plasticity states of the neuronal networks (Donato et al., 2013; Winkel et al., 2021). The firing of the PV+ interneurons mediates both memory consolidation (Ognjanovski et al., 2017) and extinction (Trouche et al., 2013; Davis et al., 2017), and optogenetic manipulation of PV+ neurons was sufficient to restore memory-related deficits induced by PNN degradation (Shi et al., 2019). We have shown that optical 

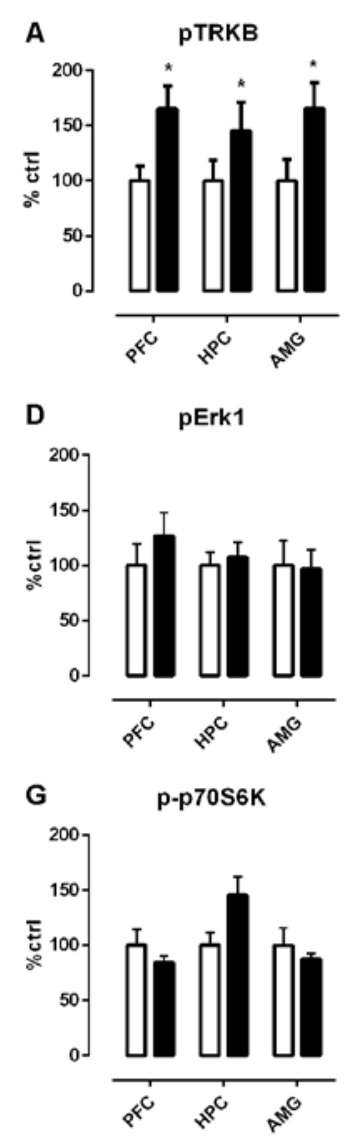

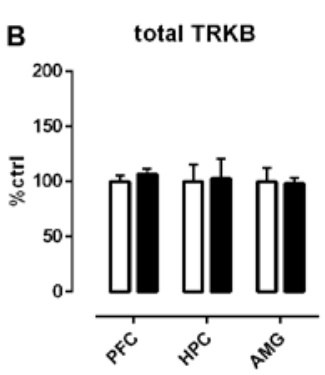

E

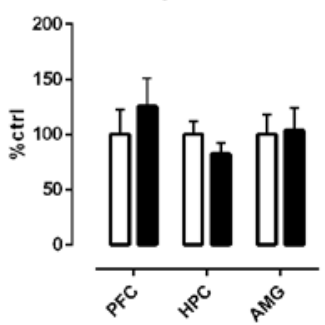

H

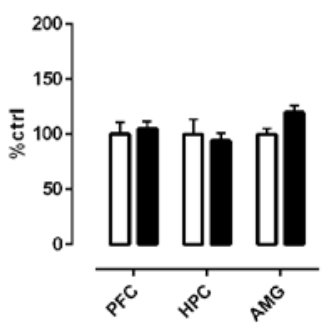

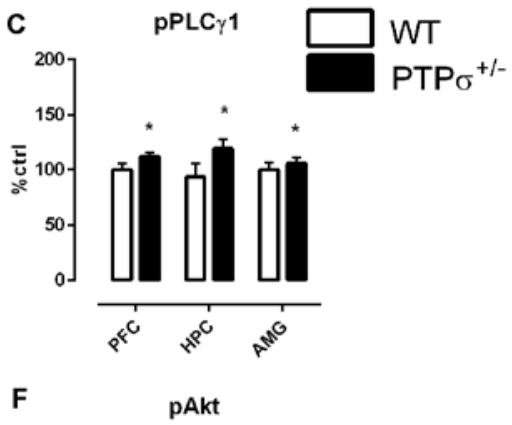

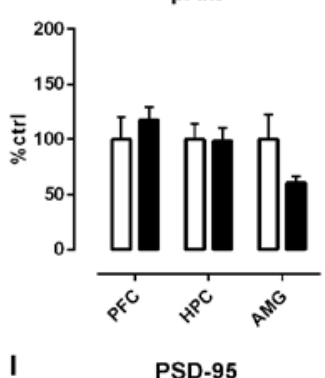

I

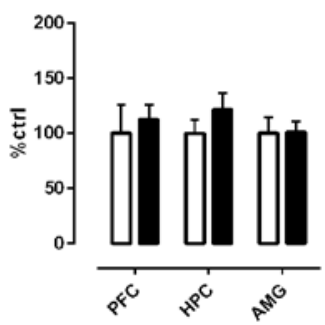

FIGURE 1 | Molecular profile of changes in plasticity-related proteins induced by PTP $\sigma$ genetic deficiency in different brain areas. (A) PTP $\sigma^{+/-}$mice have increased phosphorylation of TRKB receptors (pTRKB) and (B) no changes in total TRKB levels in the prefrontal cortex (PFC), hippocampus (HPC), and amygdala (AMG). $\mathrm{PTP}^{+/-}$mice display (C) increased phosphorylation of PLC $\gamma 1$ (pPLC $\left.\gamma 1\right)$, no changes in phosphorylation of (D,E) Erk, (F) Akt, (G) p70S6 kinase and no changes in total levels of (H) PSD-93 and (I) PSD-95 expression. Data on (A) was measured by ELISA and on (B-I) by Western blot. Data were analyzed by two-way ANOVA ${ }^{*} p<0.05$.

activation of TRKB in PV+ interneurons is alone sufficient to orchestrate and coordinate large brain networks, rendering them into a state of juvenile-like plasticity (Winkel et al., 2021).

TRKB is a well-characterized positive modulator of plasticity in the brain, essential for learning memory, and other cognitive processes (Yamada and Nabeshima, 2003; Minichiello, 2009). Learning events have been demonstrated to prompt BDNF expression and TRKB phosphorylation (Hall et al., 2000; Gooney et al., 2002), while BDNF mutations in mice and humans are known to induce learning deficits (Linnarsson et al., 1997; Dincheva et al., 2012). TRKB phosphorylation leads to activation of three major downstream signaling pathways: Sch adaptor protein recognizes phosphorylation of tyrosine 515 and activates PI3K/Akt and Ras/MEK/Erk pathways that regulate neuronal survival and neuronal differentiation (Atwal et al., 2000; Minichiello, 2009). PLC $\gamma 1$ recognizes phosphorylated tyrosine 816 and, once phosphorylated, induces signaling through calmodulin kinase-2 and CREB, thereby modulating neuronal connectivity and plasticity (Patapoutian and Reichardt, 2001; Minichiello, 2009). Specificity of the downstream pathway activation is mediated through different docking partners, and it's been demonstrated that mutation of PLC $\gamma 1$ docking site critically affects hippocampal long-term potentiation (LTP), plasticity, and learning (Minichiello et al., 2002; Gruart et al., 2007). Surprisingly, a similar mutation of the Shc recognition site, which mediates Akt and Erk activation, produces only minimal effects on BDNF signaling in vivo (Minichiello et al., 1998). Given that $\mathrm{PTP}^{+/-}$mice demonstrate an increase in PLC $\gamma 1$ activation, their phenotype of facilitated plasticity and learning is not entirely surprising. However, the reason for the specificity of activation for this particular pathway remains to be further investigated.

TRKB overexpression in a transgenic mouse line (TRKB.TK+) has yielded similar results with positive modulation of PLC $\gamma 1$ but not PI3K/Akt or Erk pathways (Koponen et al., 2004). These TRKB.TK+ mice demonstrated facilitated learning (tested in Morris water maze) similar to $\mathrm{PTP}^{+/-}$mice. However, TRKB.TK+ mice also showed improved long-term memory in both Morris water maze and fear conditioning paradigms (Koponen et al., 2004), as opposed to $\mathrm{PTP}^{+/-}$mice having impaired long-term fear conditioning and object recognition memory. However, direct comparison of these observations 
A Short-term Novel Object Recognition

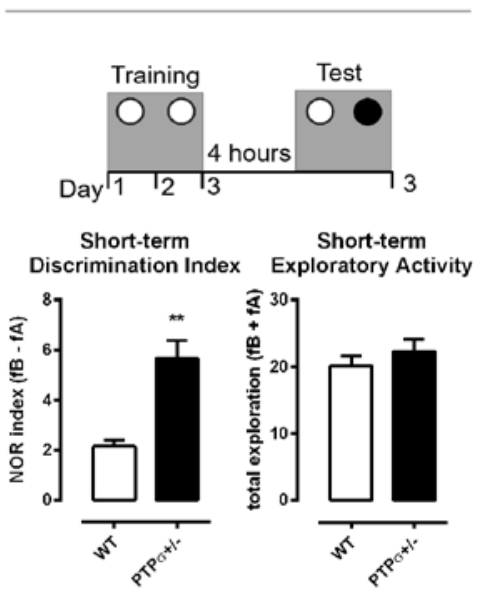

B Long-term Novel Object Recognition

C Fear Conditioning

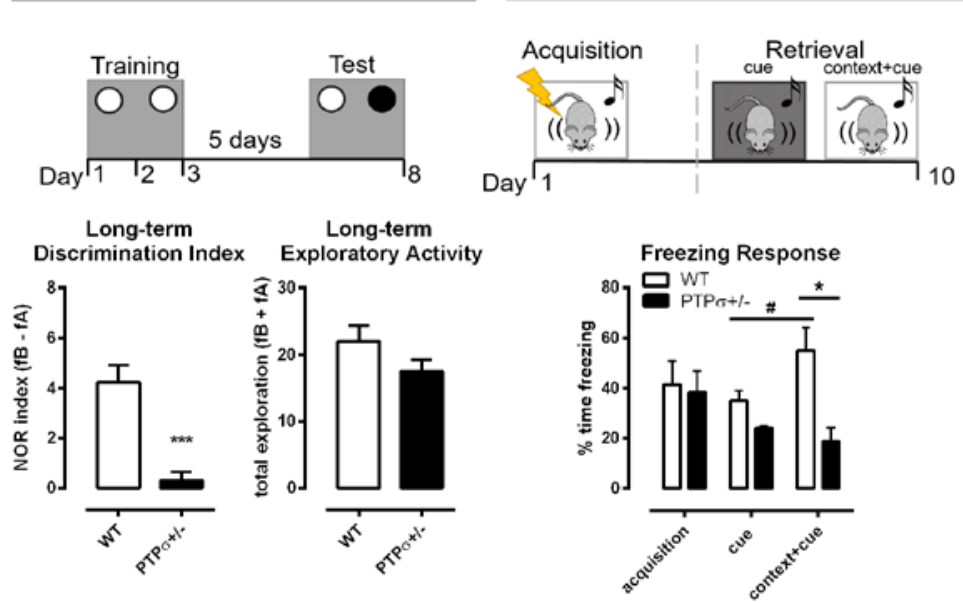

FIGURE 2 | PTP $\sigma^{+/-}$mice demonstrate improved short-term but impaired long-term memory. PTP $\sigma^{+/-}$mice have (A) improved short-term memory and (B) impaired long-term memory and no changes in the total exploratory activity in the Novel Object Recognition test. (C) The fear response triggered by the cue in the retrieval session was potentiated by the context in WT but not in the PTP $\sigma^{+/-}$mice. Data were analyzed by (A,B) Mann-Whitney test, and (C) two-way ANOVA. ${ }^{\star} p<0.05,{ }^{* \star} p<0.01,{ }^{* \star} p<0.001$. In (C): ${ }^{*} p<0.05$ (vs. WT cue), ${ }^{\star} p<0.05$ (vs. WT context+cue).

is difficult due to the timeline differences between the tests and because TRKB.TK+ mice overexpress TRKB in pyramidal cells and not in PV neurons. TRKB.TK+ were tested $48 \mathrm{~h}$ after training at the latest, when the memory traces were relatively fresh, while $\mathrm{PTP}^{+/-}$mouse memory was assessed 5-10 days after the initial learning. Moreover, even though BDNF-TRKB signaling is known to be critical for both short-term and long-term memory function (Bekinschtein et al., 2014), excessive BDNF-TRKB activation can also render previously established long-term memories labile and promote their erasure. For example, direct BDNF infusion into the infralimbic prefrontal cortex facilitates extinction of fear and drug-induced conditioned place preference memories (Peters et al., 2010; Otis et al., 2014; Kataoka et al., 2019), with similar effects achieved by TRKB facilitation by chronic antidepressant treatment (Karpova et al., 2011). Even though time and regionspecific mechanisms of BDNF-TRKB's role in memory events remain to be fully clarified, it is plausible to assume that TRKB activation has to be time-precise and transient in order to lead to robust memory acquisition. Since $\mathrm{PTP}^{+/-}$mice have chronically increased TRKB activation due to reduced dephosphorylation from PTP $\sigma$, their neuronal networks seem to acquire a state of hyperplasticity, or tonic plasticity (as opposed to the phasic plasticity in the normal brain), which allows for the enhanced acquisition of memories but not for their retention.

It is interesting that a similar dissociation between shortand long-term memories can be experimentally induced by PNN manipulation. PNN downregulation by chABC digestion or genetic knockdown of their components has been shown to improve object recognition memory for a period up to 48 h (Romberg et al., 2013; Rowlands et al., 2018). However, perineuronal nets are also indispensable for long-term memory retention, as PNN degradation has been demonstrated to impair the persistence of memories and promote their erasure in different brain areas such as the prefrontal cortex (Hylin et al., 2013; Slaker et al., 2015), hippocampus (Hylin et al., 2013; Riga et al., 2017; Shi et al., 2019), and amygdala (Gogolla et al., 2009; Xue et al., 2014; Pignataro et al., 2017). Since PTP $\sigma^{+/-}$mice have a lower number of PNN receptors available for transduction of their signals, the PNN network consolidation function in their brain is likely to be compromised, which may improve shortterm but impair long-term memory performance.

PTP $\sigma$ is a complex molecule attributed to a number of different functions. Apart from being a phosphatase and a receptor for PNNs, it is also known to be a synaptic adhesion molecule, playing an important role in excitatory synapse assembly. It binds a number of partners in both cis- and trans-synaptic manner, including SLIT and NTRK-like proteins (Slitrks; Um et al., 2014), synaptic adhesion-like molecule 3 (SALM3; Li et al., 2015b), leucine-rich repeat transmembrane protein 4 (LRRTM4; Ji et al., 2015), liprin- $\alpha$ (Bomkamp et al., 2019) and tropomyosin receptor kinase C (TRKC; Takahashi et al., 2011; Coles et al., 2014). These interactions have been demonstrated to be critical for normal excitatory synaptic formation. According to the model proposed in the literature, РТР $\sigma$ drives excitatory synapse formation through a combination of trans-synaptic interactions with partners such as TRKC (but not TRKB) and Slitrks, and intracellular signaling cascades when PТР $\sigma$ intracellular domains interact in cis with adaptor proteins (such as liprin- $\alpha$ ) and direct substrates, such as N-cadherin or TRKB (Coles et al., 2011; Han et al., 2018; Bomkamp et al., 2019). Global PTP $\sigma$ knockout and conditional deletion of PTP $\sigma$ impairs excitatory synapse transmission, leading to abnormalities in synaptic structure (Horn et al., 2012; Han et al., 2020) and reduced number of excitatory synapses 


\section{A Elevated Plus Maze}

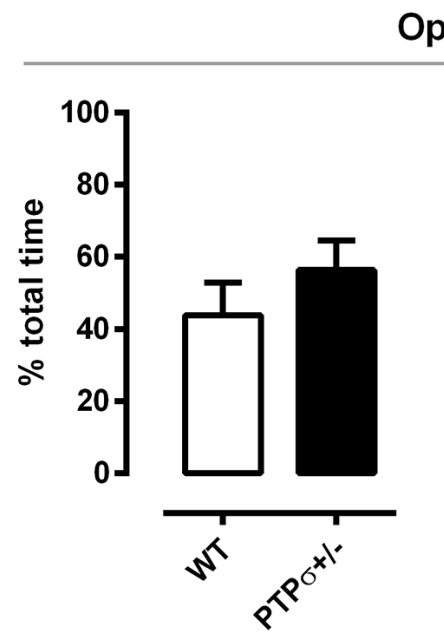

B Marble Burying

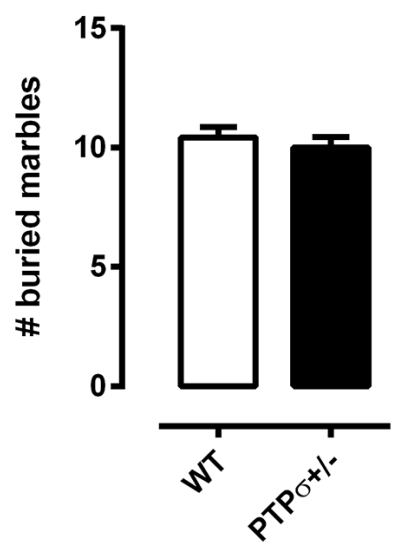

Open Arms

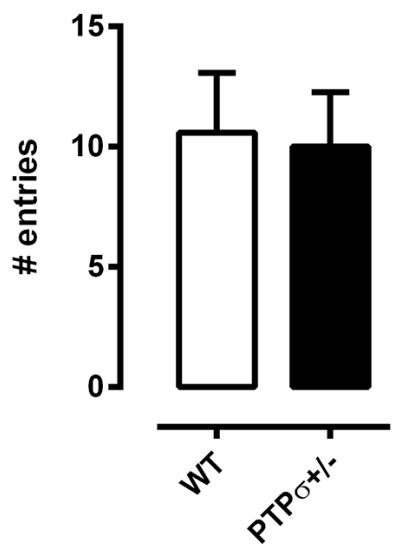

c Open Field

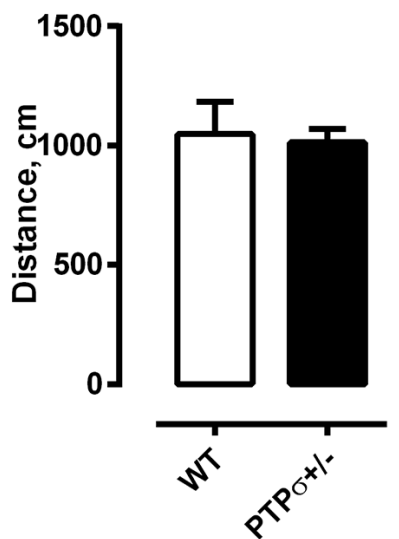

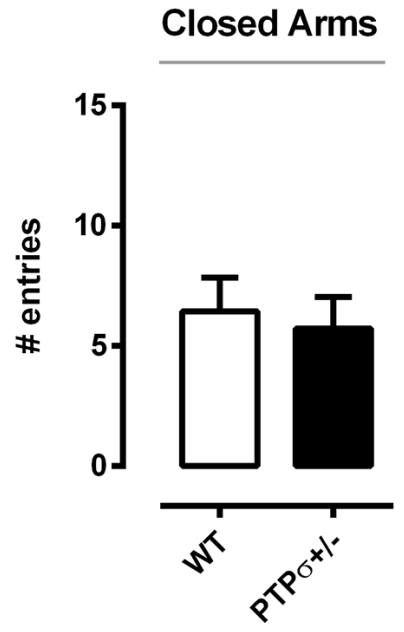

D Forced Swimming

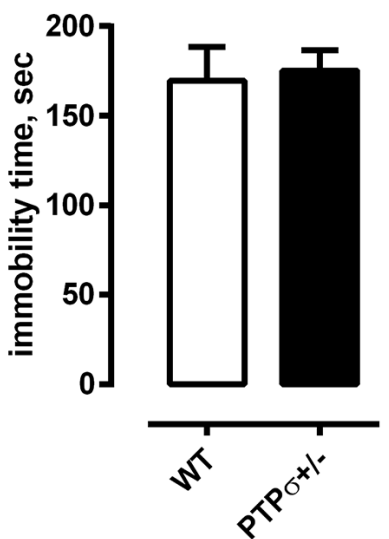

FIGURE 3 | PTP $\sigma^{+/-}$mice exhibit normal behavior in tests that do not involve cognitive flexibility. PTP ${ }^{+/-}$mice display no behavioral changes in (A) elevated plus maze, (B) marble burying, (C) open field, and (D) forced swimming tests as compared to their wild-type littermates. Data were analyzed by $t$-test (A total time, $\mathbf{C}, \mathbf{D})$ or by Mann-Whitney test (A, \# entries for Open and Closed Arms, and $\mathbf{B})$.

(Han et al., 2018, 2020). Curiously, in the present study, no difference in the number of excitatory synapses was found when comparing WT and PTP $\sigma+/-$ mouse brain. That discrepancy might be due to methodological differences. For example, in the study by Han et al. (2018) and Han et al. (2020), PTPo role on excitatory synapse development was investigated in vitro. In Han et al. (2020), PTP $\sigma$ conditional KO was used, thus it is likely that the location and developmental stage in which PTPo expression was disrupted, as well as the degree of the downregulation, were different from the conditions in our study.

PTP $\sigma$ deficiency also increases frequency but reduces the efficiency of excitatory postsynaptic currents (Horn et al., 2012; Han et al., 2020) and impairs LTP (Horn et al., 2012). LTP deficits were also observed when PTP $\sigma$ knockdown was restricted to excitatory cortical and hippocampal neurons (Kim et al., 2020). Similarly, overexpression of TRKB in pyramidal neurons, which increases TRKB phosphorylation and signaling through PLC $\gamma 1$, also impairs LTP (Koponen et al., 2004). Interestingly, Kim et al. (2020) showed that presynaptic PTP $\sigma$ deficiency selectively impairs NMDA-dependent postsynaptic currents, and it happens through a mechanism independent of PTP $\sigma$ trans-synaptic adhesion, suggesting further involvement of PTP $\sigma$ cytoplasmic phosphatase domains in this process. Even though the direct relationship between LTP and memory remains a subject to debate (Stevens, 1998; Nicoll, 2017), NMDA-dependent LTP is known to be critical for normal memory performance, and disturbances in this pathway impair memory function (Nakazawa et al., 2004; Li and Tsien, 2009; Morris, 2013; Nabavi et al., 2014). Since PTP $\sigma$ plays a substantial role in excitatory synaptic transmission and normal LTP, its partial deletion from $\mathrm{PTP}^{+/-}$mouse brain may cause deficiencies in normal synapse function and stabilization, leading to an inability of the synapses to efficiently support long-term memory maintenance. 
Evanescence of long-term memories may be a disadvantage; however, it may also be beneficial under certain conditions when memories carry over a trauma such as in post-traumatic stress disorder (PTSD). Labilization of memories has been proposed to be a potential therapeutic tool for such disorders (Kindt et al., 2009), and treatment strategies targeting both PNNs (Gogolla et al., 2009; Banerjee et al., 2017; Pignataro et al., 2017) and BDNF-TRKB system (Karpova et al., 2011; Andero and Ressler, 2012; Kataoka et al., 2019) were suggested to carry translational promise. Now that PTP $\sigma$ has been established as a missing link in the PNN-PTP $\sigma$-TRKB axis in PV interneurons, its further investigation as a potential target for PTSD treatment is promising. Small molecule compounds inhibiting PTPs and specifically PTP $\sigma$ have been discovered (Martin et al., 2012, 2014; Lazo et al., 2018; Zhang et al., 2019). Moreover, intracellular sigma peptides (ISP) that bind to PTP $\sigma$ intracellular domain and inhibit its phosphatase activity have recently been developed and successfully tested in the rodent models of spinal cord injury (Li et al., 2015a) and multiple sclerosis (Luo et al., 2018; Tran et al., 2018). ISPs are currently undergoing an FDA approval procedure and are being prepared for the first clinical trials, which bears promise for their future use in patients. However, further development and application of PTP $\sigma$-targeting treatments in humans must be carried out with caution. Long-term memory loss may come up as one potential side effect of ISP or small molecule treatment. Moreover, PTP $\sigma$ is widely expressed in different cell types in the central nervous system and beyond and regulates multiple processes, including cell adhesion, hormone immunoreactive cell functioning, and hematopoietic stem cell proliferation and migration (Elchebly et al., 1999; Quarmyne et al., 2015; Zhang et al., 2019). Therefore, modulation of PTP $\sigma$ system at the systemic level may have complex and non-direct consequences, including untoward side effects such as hormonal or hematopoietic cell dysfunction, and further research is required to ensure safety of such interventions.

In conclusion, our findings contribute to the emerging recognition of the importance of perineuronal nets and their downstream targets in neuropsychological processes in the brain and shed light on the molecular underpinnings of complex systemic events such as memory and learning. Future studies will be needed in the field to resolve the remaining questions and improve our understanding of the role of PNN-PTP $\sigma$-TRKB complex in both healthy and diseased brains.

\section{REFERENCES}

Andero, R., and Ressler, K. J. (2012). Fear extinction and BDNF: translating animal models of PTSD to the clinic. Genes Brain Behav. 11, 503-512. doi: 10.1111/j. 1601-183X.2012.00801.x

Antila, H., Autio, H., Turunen, L., Harju, K., Tammela, P., Wennerberg, K., et al. (2014). Utilization of in situ ELISA method for examining Trk receptor phosphorylation in cultured cells. J. Neurosci. Methods 222, 142-146. doi: 10.1016/j.jneumeth.2013.11.001

Atwal, J. K., Massie, B., Miller, F. D., and Kaplan, D. R. (2000). The TrkB-Shc site signals neuronal survival and local axon growth via MEK and PI3-Kinase. Neuron 27, 265-277. doi: 10.1016/s0896-6273(00)00035-0

\section{DATA AVAILABILITY STATEMENT}

The dataset presented in this study can be found at Figshare, DOI: 10.6084/m9.figshare.c.5316767.

\section{ETHICS STATEMENT}

The animal study was reviewed and approved by Experimental Animal Ethical Committee of Southern Finland (ESAVI/38503/2019).

\section{AUTHOR CONTRIBUTIONS}

$\mathrm{PC}, \mathrm{CB}$, and EC designed the study. AL, PC, RM, SF, and $\mathrm{CB}$ performed the experiments. $\mathrm{AL}, \mathrm{PC}$, and $\mathrm{CB}$ analyzed the data. $\mathrm{AL}$ wrote the manuscript draft. $\mathrm{AL}, \mathrm{PC}, \mathrm{RM}, \mathrm{SF}, \mathrm{CB}$, and $\mathrm{EC}$ revised the manuscript. All authors contributed to the article and approved the submitted version.

\section{FUNDING}

This work was supported by Doctoral Program in Integrative Life Science, Jalmari ja Rauha Ahokkaan Säätiö grant, Centre for International Mobility (CIMO) Grant TM-16-10112, by grants from European Research Council (\#322742), EU Joint Programme-Neurodegenerative Disease Research (JPND) CircProt (\#301225 and \#643417), Sigrid Jusélius Foundation, Jane and Aatos Erkko Foundation, and the Academy of Finland (\#294710 and \#307416). None of the funders had a role in the data acquisition, analysis or manuscript preparation.

\section{ACKNOWLEDGMENTS}

We thank Nelli Koivisto and Vootele Võikar (Mouse Behavioral Phenotyping Facility, Laboratory Animal Center-University of Helsinki) for their expert advice on animal research and Sulo Kolehmainen and Seija Lågas for technical help.

\section{SUPPLEMENTARY MATERIAL}

The Supplementary Material for this article can be found online at: https://www.frontiersin.org/articles/10.3389/fnsyn. 2021.672475/full\#supplementary-material.

Banerjee, S. B., Gutzeit, V. A., Baman, J., Aoued, H. S., Doshi, N. K., Liu, R. C. et al. (2017). Perineuronal nets in the adult sensory cortex are necessary for fear learning. Neuron 95, 169-179.e3. doi: 10.1016/j.neuron.2017.06.007

Bekinschtein, P., Cammarota, M., and Medina, J. H. (2014). BDNF and memory processing. Neuropharmacology 76, 677-683. doi: 10.1016/j.neuropharm.2013. 04.024

Bomkamp, C., Padmanabhan, N., Karimi, B., Ge, Y., Chao, J. T., Loewen, C. J. R., et al. (2019). Mechanisms of PTP $\sigma$-mediated presynaptic differentiation. Front. Synaptic Neurosci. 11:17. doi: 10.3389/fnsyn.2019.00017

Casarotto, P. C., Girych, M., Fred, S. M., Kovaleva, V., Moliner, R., Enkavi, G., et al. (2021). Antidepressant drugs act by directly binding to TRKB neurotrophin receptors. Cell 84, 1299-1313. doi: 10.1016/j.cell.2021.01.034 
Castrén, E., and Antila, H. (2017). Neuronal plasticity and neurotrophic factors in drug responses. Mol. Psychiatry 22, 1085-1095. doi: 10.1038/mp. 2017.61

Christensen, A. C., Lensjø, K. K., Lepperød, M. E., Dragly, S. A., Sutterud, H., Blackstad, J. S., et al. (2021). Perineuronal nets stabilize the grid cell network. Nat. Commun. 12, 1-17. doi: 10.1038/s41467-020-20241-w

Coles, C. H., Mitakidis, N., Zhang, P., Elegheert, J., Lu, W., Stoker, A. W., et al. (2014). Structural basis for extracellular cis and trans RPTPo signal competition in synaptogenesis. Nat. Commun. 5, 1-12. doi: 10.1038/ncomms 6209

Coles, C. H., Shen, Y., Tenney, A. P., Siebold, C., Sutton, G. C., Lu, W., et al. (2011). Proteoglycan-specific molecular switch for RPTP $\sigma$ clustering and neuronal extension. Science 332, 484-488. doi: 10.1126/science.1200840

Cunha, C., Brambilla, R., and Thomas, K. L. (2010). A simple role for BDNF in learning and memory? Front. Mol. Neurosci. 3:1. doi: 10.3389/neuro.02.001. 2010

Davis, P., Zaki, Y., Maguire, J., and Reijmers, L. G. (2017). Cellular and oscillatory substrates of fear extinction learning. Nat. Neurosci. 20, 1624-1633. doi: 10.1038/nn.4651

Deepa, S. S., Carulli, D., Galtrey, C., Rhodes, K., Fukuda, J., Mikami, T., et al. (2006). Composition of perineuronal net extracellular matrix in rat brain: a different disaccharide composition for the net-associated proteoglycans. J. Biol. Chem. 281, 17789-17800. doi: 10.1074/jbc.M600544200

Dere, E., Huston, J. P., and De Souza Silva, M. A. (2007). The pharmacology, neuroanatomy and neurogenetics of one-trial object recognition in rodents. Neurosci. Biobehav. Rev. 31, 673-704. doi: 10.1016/j.neubiorev.2007.01.005

Dincheva, I., Glatt, C. E., and Lee, F. S. (2012). Impact of the BDNF Val66Met polymorphism on cognition: implications for behavioral genetics. Neuroscientist 18, 439-451. doi: 10.1177/1073858411431646

Donato, F., Rompani, S. B., and Caroni, P. (2013). Parvalbumin-expressing basket-cell network plasticity induced by experience regulates adult learning. Nature 504, 272-276. doi: 10.1038/nature12866

Elchebly, M., Wagner, J., Kennedy, T. E., Lanctôt, C., Michaliszyn, E., Itié, A., et al. (1999). Neuroendocrine dysplasia in mice lacking protein tyrosine phosphatase б. Nat. Genet. 21, 330-333. doi: 10.1038/6859

Faux, C., Hawadle, M., Nixon, J., Wallace, A., Lee, S., Murray, S., et al. (2007). $\mathrm{PTP} \sigma$ binds and dephosphorylates neurotrophin receptors and can suppress NGF-dependent neurite outgrowth from sensory neurons. Biochim. Biophys. Acta Mol. Cell Res. 1773, 1689-1700. doi: 10.1016/j.bbamcr.2007.06.008

Fawcett, J. W., Oohashi, T., and Pizzorusso, T. (2019). The roles of perineuronal nets and the perinodal extracellular matrix in neuronal function. Nat. Rev. Neurosci. 20, 451-465. doi: 10.1038/s41583-019-0196-3

Gogolla, N., Caroni, P., Lüthi, A., and Herry, C. (2009). Perineuronal nets protect fear memories from erasure. Science 325, 1258-1261. doi: 10.1126/science. 1174146

Gooney, M., Shaw, K., Kelly, Á., O’Mara, S. M., and Lynch, M. A. (2002). Long-term potentiation and spatial learning are associated with increased phosphorylation of TrkB and extracellular signal-regulated kinase (ERK) in the dentate gyrus: evidence for a role for brain-derived neurotrophic factor. Behav. Neurosci. 116, 455-463. doi: 10.1037//0735-7044.116.3.455

Gruart, A., Sciarretta, C., Valenzuela-Harrington, M., Delgado-García, J. M., and Minichiello, L. (2007). Mutation at the TrkB PLC $\gamma$-docking site affects hippocampal LTP and associative learning in conscious mice. Learn. Mem. 14, 54-62. doi: 10.1101/lm.428307

Hall, J., Thomas, K. L., and Everitt, B. J. (2000). Rapid and selective induction of BDNF expression in the hippocampus during contextual learning. Nat. Neurosci. 3, 533-535. doi: 10.1038/75698

Han, K. A., Ko, J. S., Pramanik, G., Kim, J. Y., Tabuchi, K., Um, J. W., et al. (2018). PTPo drives excitatory presynaptic assembly via various extracellular and intracellular mechanisms. J. Neurosci. 38, 6700-6721. doi: 10.1523/JNEUROSCI.0672-18.2018

Han, K. A., Lee, H. Y., Lim, D., Shin, J., Yoon, T. H., Lee, C., et al. (2020). PTP $\sigma$ controls presynaptic organization of neurotransmitter release machinery at excitatory synapses. iScience 23:101203. doi: 10.1016/j.isci.2020. 101203

Hockfield, S., and McKay, R. D. G. (1983). A surface antigen expressed by a subset of neurons in the vertebrate central nervous system. Proc. Natl. Acad. Sci. US A 80, 5758-5761. doi: 10.1073/pnas.80.18.5758
Horn, K. E., Xu, B., Gobert, D., Hamam, B. N., Thompson, K. M., Wu, C. L., et al. (2012). Receptor protein tyrosine phosphatase sigma regulates synapse structure, function and plasticity. J. Neurochem. 122, 147-161. doi: 10.1111/j. 1471-4159.2012.07762.x

Houston, F. P., Stevenson, G. D., McNaughton, B. L., and Barnes, C. A. (1999). Effects of age on the generalization and incubation of memory in the F344 rat. Learn. Mem. 6, 111-119.

Hylin, M. J., Orsi, S. A., Moore, A. N., and Dash, P. K. (2013). Disruption of the perineuronal net in the hippocampus or medial prefrontal cortex impairs fear conditioning. Learn. Mem. 20, 267-273. doi: 10.1101/lm.030197.112

Ji, S. K., Gopal, P., Ji, W. U., Ji, S. S., Dongmin, L., Kee, H. K., et al. (2015). Ptp functions as a presynaptic receptor for the glypican-4/LRRTM4 complex and is essential for excitatory synaptic transmission. Proc. Natl. Acad. Sci. U S A 112, 1874-1879. doi: 10.1073/pnas.1410138112

Kaczorowski, C. C., and Disterhoft, J. F. (2009). Memory deficits are associated with impaired ability to modulate neuronal excitability in middle-aged mice. Learn. Mem. 16, 362-366. doi: 10.1101/lm.1365609

Karpova, N. N., Pickenhagen, A., Lindholm, J., Tiraboschi, E., Kulesskaya, N., Ágústsdóttir, A., et al. (2011). Fear erasure in mice requires synergy between antidepressant drugs and extinction training. Science 334, 1731-1734. doi: $10.1126 /$ science. 1214592

Kataoka, T., Fuchikami, M., Nojima, S., Nagashima, N., Araki, M., Omura, J., et al. (2019). Combined brain-derived neurotrophic factor with extinction training alleviate impaired fear extinction in an animal model of post-traumatic stress disorder. Genes Brain Behav. 18:e12520. doi: 10.1111/gbb.12520

Kim, D., Jeong, H., Lee, J., Ghim, J. W., Her, E. S., Lee, S. H., et al. (2016). Distinct roles of parvalbumin- and somatostatin-expressing interneurons in working memory. Neuron 92, 902-915. doi: 10.1016/j.neuron.2016.09.023

Kim, K., Shin, W., Kang, M., Lee, S., Kim, D., Kang, R., et al. (2020) Presynaptic PTP $\sigma$ regulates postsynaptic NMDA receptor function through direct adhesion-independent mechanisms. eLife 9:e54224. doi: 10.7554/eLife. 54224

Kindt, M., Soeter, M., and Vervliet, B. (2009). Beyond extinction: erasing human fear responses and preventing the return of fear. Nat. Neurosci. 12, 256-259. doi: $10.1038 / \mathrm{nn} .2271$

Koponen, E., Võikar, V., Riekki, R., Saarelainen, T., Rauramaa, T., Rauvala, H. et al. (2004). Transgenic mice overexpressing the full-length neurotrophin receptor trkB exhibit increased activation of the trkB-PLC $\gamma$ pathway, reduced anxiety and facilitated learning. Mol. Cell. Neurosci. 26, 166-181. doi: 10.1016/j. mcn.2004.01.006

Korotkova, T., Fuchs, E. C., Ponomarenko, A., von Engelhardt, J., and Monyer, H. (2010). NMDA receptor ablation on parvalbumin-positive interneurons impairs hippocampal synchrony, spatial representations and working memory. Neuron 68, 557-569. doi: 10.1016/j.neuron.2010.09.017

Kosaka, T., and Heizmann, C. W. (1989). Selective staining of a population of parvalbumin-containing GABAergic neurons in the rat cerebral cortex by lectins with specific affinity for terminal $\mathrm{N}$-acetylgalactosamine. Brain Res. 483, 158-163. doi: 10.1016/0006-8993(89)90048-6

Kurihara, D., and Yamashita, T. (2012). Chondroitin sulfate proteoglycans down-regulate spine formation in cortical neurons by targeting tropomyosinrelated kinase B (TrkB) protein. J. Biol. Chem. 287, 13822-13828. doi: $10.1074 /$ jbc.M111.314070

Lazo, J. S., McQueeney, K. E., Burnett, J. C., Wipf, P., and Sharlow, E. R. (2018). Small molecule targeting of PTPs in cancer. Int. J. Biochem. Cell Biol. 96, 171-181. doi: 10.1016/j.biocel.2017.09.011

Lesnikova, A., Casarotto, P. C., Fred, S. M., Voipio, M., Winkel, F., Steinzeig, A., et al. (2021). Chondroitinase and antidepressants promote plasticity by releasing TRKB from dephosphorylating control of PTP $\sigma$ in parvalbumin neurons. J. Neurosci. 41, 972-980. doi: 10.1523/JNEUROSCI.222820.2020

Li, F., and Tsien, J. Z. (2009). Memory and the NMDA receptors. N. Engl. J. Med. 361, 302-303. doi: 10.1056/NEJMcibr0902052

Li, H., Wong, C., Li, W., Ruven, C., He, L., Wu, X., et al. (2015a). Enhanced regeneration and functional recovery after spinal root avulsion by manipulation of the proteoglycan receptor PTPб. Sci. Rep. 5, 1-14. doi: $10.1038 /$ srep 14923

Li, Y., Zhang, P., Choi, T. Y., Park, S. K., Park, H., Lee, E. J., et al. (2015b). Splicingdependent trans-synaptic SALM3-LAR-RPTP interactions regulate excitatory 
synapse development and locomotion. Cell Rep. 12, 1618-1630. doi: 10.1016/j. celrep.2015.08.002

Linnarsson, S., Björklund, A., and Ernfors, P. (1997). Learning deficit in BDNF mutant mice. Eur. J. Neurosci. 9, 2581-2587. doi: 10.1111/j.1460-9568.1997. tb01687.x

Luo, F., Tran, A. P., Xin, L., Sanapala, C., Lang, B. T., Silver, J., et al. (2018). Modulation of proteoglycan receptor PTP $\sigma$ enhances MMP-2 activity to promote recovery from multiple sclerosis. Nat. Commun. 9, 1-16. doi: 10.1016/j.neuroscience.2004.11.017

Manders, E. M. M., Verbeek, F. J., and Aten, J. A. (1993). Measurement of colocalization of objects in dual-colour confocal images. J. Microsc. 169, 375-382. doi: 10.1111/j.1365-2818.1993.tb03313.x

Martin, K. R., Narang, P., Medina-Franco, J. L., Meurice, N., and MacKeigan, J. P. (2014). Integrating virtual and biochemical screening for protein tyrosine phosphatase inhibitor discovery. Methods 65, 219-228. doi: 10.1016/j.ymeth. 2013.08.013

Martin, K. R., Narang, P., Xu, Y., Kauffman, A. L., Petit, J., Xu, H. E., et al. (2012). Identification of small molecule inhibitors of PTPo through an integrative virtual and biochemical approach. PLoS One 7:e50217. doi: 10.1371/journal. pone. 0050217

Minichiello, L. (2009). TrkB signalling pathways in LTP and learning. Nat. Rev. Neurosci. 10, 850-860. doi: 10.1038/nrn2738

Minichiello, L., Calella, A. M., Medina, D. L., Bonhoeffer, T., Klein, R., and Korte, M. (2002). Mechanism of TrkB-mediated hippocampal long-term potentiation. Neuron 36, 121-137. doi: 10.1016/s0896-6273(02)00942-x

Minichiello, L., Casagranda, F., Tatche, R. S., Stucky, C. L., Postigo, A., Lewin, G. R., et al. (1998). Point mutation in trkB causes loss of NT4-dependent neurons without major effects on diverse BDNF responses. Neuron 21, 335-345. doi: 10.1016/s0896-6273(00)80543-7

Minichiello, L., Korte, M., Wolfer, D., Kühn, R., Unsicker, K., Cestari, V., et al. (1999). Essential role for TrkB receptors in hippocampus-mediated learning. Neuron 24, 401-414. doi: 10.1016/s0896-6273(00)80853-3

Morris, R. G. M. (2013). NMDA receptors and memory encoding. Neuropharmacology 74, 32-40. doi: 10.1016/j.neuropharm.2013.04.014

Motulsky, H. J., and Brown, R. E. (2006). Detecting outliers when fitting data with nonlinear regression-A new method based on robust nonlinear regression and the false discovery rate. BMC Bioinform. 7:123. doi: 10.1186/1471-2105-7-123

Nabavi, S., Fox, R., Proulx, C. D., Lin, J. Y., Tsien, R. Y., and Malinow, R. (2014). Engineering a memory with LTD and LTP. Nature 511, 348-352. doi: 10.1038/nature13294

Nakazawa, K., McHugh, T. J., Wilson, M. A., and Tonegawa, S. (2004). NMDA receptors, place cells and hippocampal spatial memory. Nat. Rev. Neurosci. 5, 361-372. doi: 10.1038/nrn1385

Nicoll, R. A. (2017). A brief history of long-term potentiation. Neuron 93, 281-290. doi: 10.1016/j.neuron.2016.12.015

Njung'e, K., and Handley, S. L. (1991). Evaluation of marble-burying behavior as a model of anxiety. Pharmacol. Biochem. Behav. 38, 63-67. doi: 10.1016/00913057(91)90590-x

Ognjanovski, N., Schaeffer, S., Wu, J., Mofakham, S., Maruyama, D., Zochowski, M., et al. (2017). Parvalbumin-expressing interneurons coordinate hippocampal network dynamics required for memory consolidation. Nat. Commun. 8, 1-14. doi: 10.1038/ncomms15039

Oler, J. A., and Markus, E. J. (1998). Age-related deficits on the radial maze and in fear conditioning: hippocampal processing and consolidation. Hippocampus 8, 402-415. doi: 10.1002/(SICI)1098-1063(1998)8:4<402::AID-HIPO8>3. $0 . \mathrm{CO} ; 2-\mathrm{I}$

Otis, J. M., Fitzgerald, M. K., and Mueller, D. (2014). Infralimbic BDNF/TrkB enhancement of GluN2B currents facilitates extinction of a cocaine-conditioned place preference. J. Neurosci. 34, 6057-6064. doi: 10.1523/JNEUROSCI.4980-13.2014

Patapoutian, A., and Reichardt, L. F. (2001). Trk receptors: mediators of neurotrophin action. Curr. Opin. Neurobiol. 11, 272-280. doi: 10.1016/s09594388(00)00208-7

Peters, J., Dieppa-Perea, L. M., Melendez, L. M., and Quirk, G. J. (2010). Induction of fear extinction with hippocampal-lnfralimbic BDNF. Science 328, 1288-1290. doi: 10.1126/science.1186909

Pignataro, A., Pagano, R., Guarneri, G., Middei, S., and Ammassari-Teule, M. (2017). Extracellular matrix controls neuronal features that mediate the persistence of fear. Brain Struct. Funct. 222, 3889-3898. doi: 10.1007/s00429 017-1440-0

Pizzorusso, T., Medini, P., Berardi, N., Chierzi, S., Fawcett, J. W., and Maffei, L. (2002). Reactivation of ocular dominance plasticity in the adult visual cortex. Science 298, 1248-1251. doi: 10.1126/science.1072699

Quarmyne, M., Doan, P. L., Himburg, H. A., Yan, X., Nakamura, M., Zhao, L., et al. (2015). Protein tyrosine phosphatase-ó regulates hematopoietic stem cell-repopulating capacity. J. Clin. Invest. 125, 177-182. doi: 10.1172/JCI 77866

Riga, D., Kramvis, I., Koskinen, M. K., van Bokhoven, P., van der Harst, J. E., Heistek, T. S., et al. (2017). Hippocampal extracellular matrix alterations contribute to cognitive impairment associated with a chronic depressive-like state in rats. Sci. Transl. Med. 9:eaai8753. doi: 10.1126/scitranslmed. aai8753

Romberg, C., Yang, S., Melani, R., Andrews, M. R., Horner, A. E., Spillantini, M. G., et al. (2013). Depletion of perineuronal nets enhances recognition memory and long-term depression in the perirhinal cortex. J. Neurosci. 33, 7057-7065. doi: 10.1523/JNEUROSCI.6267-11.2013

Rowlands, D., Lensjø, K. K., Dinh, T., Yang, S., Andrews, M. R., Hafting, T., et al. (2018). Aggrecan directs extracellular matrix-mediated neuronal plasticity. J. Neurosci. 38, 10102-10113. doi: 10.1523/JNEUROSCI.1122-18.2018

Shen, H. H. (2018). Perineuronal nets gain prominence for their role in learning, memory and plasticity. Proc. Natl. Acad. Sci. U S A 115, 9813-9815. doi: 10.1073/pnas.1815273115

Shen, Y., Tenney, A. P., Busch, S. A., Horn, K. P., Cuascut, F. X., Liu, K., et al. (2009). PTP $\sigma$ Is a receptor for chondroitin sulfate proteoglycan, an inhibitor of neural regeneration. Science 326, 592-596. doi: 10.1126/science.1178310

Shi, W., Wei, X., Wang, X., Du, S., Liu, W., Song, J., et al. (2019). Perineuronal nets protect long-term memory by limiting activity-dependent inhibition from parvalbumin interneurons. Proc. Natl. Acad. Sci. U S A 116, 27063-27073. doi: 10.1073/pnas.1902680116

Slaker, M., Churchill, L., Todd, R. P., Blacktop, J. M., Zuloaga, D. G., Raber, J., et al. (2015). Removal of perineuronal nets in the medial prefrontal cortex impairs the acquisition and reconsolidation of a cocaine-induced conditioned place preference memory. J. Neurosci. 35, 4190-4202. doi: 10.1523/JNEUROSCI. 3592-14.2015

Sorg, B. A., Berretta, S., Blacktop, J. M., Fawcett, J. W., Kitagawa, H., Kwok, J. C. F., et al. (2016). Casting a wide net: role of perineuronal nets in neural plasticity. J. Neurosci. 36, 11459-11468. doi: 10.1523/JNEUROSCI.2351-16.2016

Stevens, C. F. (1998). A million dollar question: does LTP = memory? Neuron 20, 1-2. doi: 10.1016/s0896-6273(00)80426-2

Stoehr, J. D., and Wenk, G. L. (1995). Effects of age and lesions of the nucleus basalis on contextual fear conditioning. Psychobiology 23, 173-177. doi: 10.3758/BF03332019

Takahashi, H., and Craig, A. M. (2013). Protein tyrosine phosphatases PTP $\delta$, PTPS and LAR: Presynaptic hubs for synapse organization. Trends Neurosci. 36, 522-534. doi: 10.1016/j.tins.2013.06.002

Takahashi, H., Arstikaitis, P., Prasad, T., Bartlett, T. E., Wang, Y. T., Murphy, T. H., et al. (2011). Postsynaptic TrkC and presynaptic PTP $\sigma$ function as a bidirectional excitatory synaptic organizing complex. Neuron 69, 287-303. doi: 10.1016/j.neuroscience.2008.06.043

Testa, D., Prochiantz, A., and Di Nardo, A. A. (2019). Perineuronal nets in brain physiology and disease. Semin. Cell Dev. Biol. 89, 125-135. doi: 10.1016/j. semcdb.2018.09.011

Thoenen, H. (1995). Neurotrophins and neuronal plasticity. Science 270, 593-598. doi: $10.1126 /$ science. 270.5236 .593

Thompson, K. M., Uetani, N., Manitt, C., Elchebly, M., Tremblay, M. L., and Kennedy, T. E. (2003). Receptor protein tyrosine phosphatase sigma inhibits axonal regeneration and the rate of axon extension. Mol. Cell. Neurosci. 23, 681-692. doi: 10.1016/S1044-7431(03)00120-9

Tran, A. P., Sundar, S., Yu, M., Lang, B. T., and Silver, J. (2018). Modulation of receptor protein tyrosine phosphatase sigma increases chondroitin sulfate proteoglycan degradation through cathepsin B secretion to enhance axon outgrowth. J. Neurosci. 38, 5399-5414. doi: 10.1523/JNEUROSCI.321417.2018

Trouche, S., Sasaki, J. M., Tu, T., and Reijmers, L. G. (2013). Fear extinction causes target-specific remodeling of perisomatic inhibitory synapses. Neuron 80, 1054-1065. doi: 10.1016/j.neuron.2013.07.047 
Um, J. W., Kim, K. H., Park, B. S., Choi, Y., Kim, D., Kim, C. Y., et al. (2014). Structural basis for LAR-RPTP/Slitrk complex-mediated synaptic adhesion. Nat. Commun. 5, 1-16. doi: 10.1038/ncomms6423

Umemori, J., Winkel, F., Didio, G., Llach Pou, M., and Castrén, E. (2018). iPlasticity: induced juvenile-like plasticity in the adult brain as a mechanism of antidepressants. Psychiatry Clin. Neurosci. 72, 633-653. doi: 10.1111/pcn. 12683

Wallace, M. J., Batt, J., Fladd, C. A., Henderson, J. T., Skarnes, W., and Rotin, D. (1999). Neuronal defects and posterior pituitary hypoplasia in mice lacking the receptor tyrosine phosphatase РTPб. Nat. Genet. 21, 334-338. doi: $10.1038 / 6866$

Wang, D., and Fawcett, J. (2012). The perineuronal net and the control of CNS plasticity. Cell Tissue Res. 349, 147-160. doi: 10.1007/s00441-0121375-y

Winkel, F., Ryazantseva, M., Voigt, M. B., Didio, G., Lilja, A., Pou, M. L., et al. (2021). Pharmacological and optical activation of TrkB in Parvalbumin interneurons regulates intrinsic states to orchestrate cortical plasticity. Mol. Psychiatry, in press.

Xue, Y. X., Xue, L. F., Liu, J. F., He, J., Deng, J. H., Sun, S. C., et al. (2014). Depletion of perineuronal nets in the amygdala to enhance the erasure of drug memories. J. Neurosci. 34, 6647-6658. doi: 10.1523/JNEUROSCI.539013.2014

Yamada, K., and Nabeshima, T. (2003). Brain-derived neurotrophic factor/TrkB signaling in memory processes. J. Pharmacol. Sci. 91, 267-270. doi: 10.1254/jphs.91.267

Zhang, Y., Roos, M., Himburg, H., Termini, C. M., Quarmyne, M., Li, M., et al. (2019). РТРб inhibitors promote hematopoietic stem cell regeneration. Nat. Commun. 10, 1-15. doi: 10.1038/s41467-019-11490-5

Conflict of Interest: The authors declare that the research was conducted in the absence of any commercial or financial relationships that could be construed as a potential conflict of interest.

Copyright (C) 2021 Lesnikova, Casarotto, Moliner, Fred, Biojone and Castrén. This is an open-access article distributed under the terms of the Creative Commons Attribution License (CC BY). The use, distribution or reproduction in other forums is permitted, provided the original author(s) and the copyright owner(s) are credited and that the original publication in this journal is cited, in accordance with accepted academic practice. No use, distribution or reproduction is permitted which does not comply with these terms. 